\title{
Interventions for Human Frailty: Physical Activity as a Model
}

\author{
Linda P. Fried \\ Columbia University Medical Center, New York, New York 10032 \\ Correspondence: Ipfried@columbia.edu
}

In the last 100 years, populations in developed countries have experienced an unprecedented addition of 30 years to life expectancy. Developing countries are now experiencing this same phenomenon, but over a shorter time frame. With this success comes the challenge of maximizing health and vitality across these added years. The compression of morbidity to the latest point in the human life span could unleash a sustained third demographic dividend that benefits all of society. To accomplish this, society needs to invest in the prevention and treatment of frailty, as well as in the prevention of chronic diseases at every age and stage of life. A model intervention, physical activity, may offer a road map.

\section{COMPLETING THE TRANSITION TO A WORLD OF LONGER LIVES: OPTIMIZING HEALTH ACROSS OUR LONGER LIFE COURSE}

In the last 100 years, developed countries have experienced the unprecedented addition of 30 - and more-years to life expectancy. Many developing countries are now experiencing this same extension in life expectancy, but generally over a much more compressed time frame of approximately 40 years. In all of these societies, this unprecedented addition of years of life has been because of public health interventions that have targeted infectious diseases and decreased early childhood and maternal mortality. Having now added, essentially, a new stage of life, the critical challenge is to understand how to maximize health and vitality across these longer years. Accomplishing this is essential to unleashing the opportunities and benefits of our longer lives - for older adults themselves and for all ages (Fried 2015). This goal has been expressed as the need to "compress morbidity" to the latest point in the human life span so that people live free of the diseases and conditions of old age for much of that old age (Fries 2001). If accomplished, a compression of morbidity could unleash a sustained third demographic dividend for all of society. However, to accomplish this requires society investing in creating what we could term a new life stage in which a healthy older population is able to make significant contributions to societal well-being and productivity (Fried in press a).

Accomplishing this compression of morbidity requires two significant components. First is investing in the prevention of the development of chronic diseases at every age and stage of life, which is described as a life course approach to prevention (Fried in press a). There is evidence that people who arrive at age 70 in good health

Editors: S. Jay Olshansky, George M. Martin, and James L. Kirkland

Additional Perspectives on Aging available at www.perspectivesinmedicine.org

Copyright (C) 2016 Cold Spring Harbor Laboratory Press; all rights reserved; doi: 10.1101/cshperspect.a025916

Cite this article as Cold Spring Harb Perspect Med 2016;6:a025916 


\section{L.P. Fried}

are at high likelihood of remaining healthy into their later years (Fried in press a). On the other hand, those with cumulative exposures to adverse risk factors across childhood and adulthood manifest single and then multiple diseases as they get older, and are likely to become disabled secondary to these diseases as early as their 50s and 60s (Wolinsky et al. 1983; Levine and Crimmins 2014; Geronimus et al. 2015; Fried and Ferrucci, in press).

The second approach focuses on optimizing health and preventing or slowing the onset of frailty, dementia, multimorbidity, and disability in older age itself. The remainder of this article considers the issue of frailty and the opportunities for delaying, preventing, or treating frailty, considering insights offered from a model intervention: physical activity.

\section{AGING AND DISEASE}

Population-based research is now offering evidence, across multiple studies, that the process of aging can be distinguished from the processes and consequences of diseases. The first stage of such research, over the last 50 years, showed that diseases of specific organ systems, such as atherosclerotic disease of the heart, brain, and peripheral vasculature, could be understood mechanistically as processes distinct from aging itself. These observations led to substantial research that showed that many chronic diseases are, in fact, preventable into the oldest ages. The implications, of course, are that these diseases were not inevitable with aging or, at least, not tied to a chronological age. Other innovative observations have suggested that a focus on investigating individual end-organ diseases misses a major conclusion of mechanistic research: that there are shared risk factors and etiologic pathways for multiple chronic diseases. At the behavioral level, these risk factors include physical activity, smoking, and diet, and, at the intrinsic level, there are mechanisms in common for multiple chronic diseases, such as inflammation (Tinetti and Fried 2004; Fried and Ferrucci, in press).

Parallel research has been increasingly seeking to characterize, in humans, the independent contributions of aging itself to health outcomes independent of superimposed chronic diseases. Interestingly, in multivariate analyses in a population-based cohort study, the Cardiovascular Health Study, specific chronic diseases are the independent predictors of 5-year mortality into the oldest ages; however, after 85 years, age becomes an additional independent predictor (Fig. 1). This suggests the influence of biologic

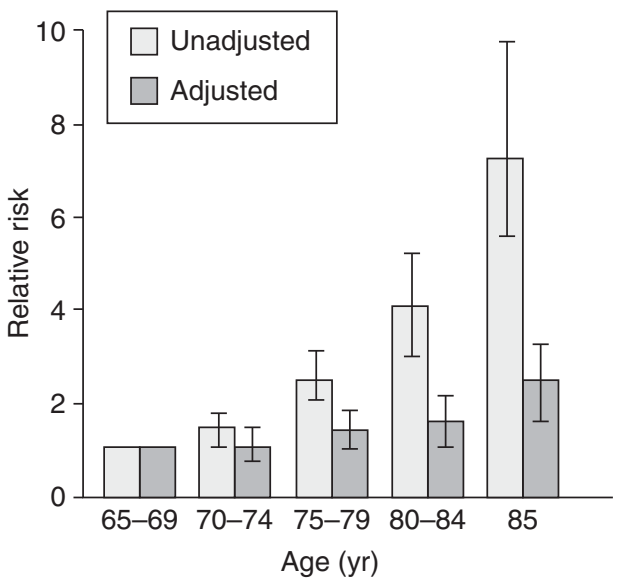

Figure 1. Age emerges as an independent predictor of mortality, independent of chronic diseases, beginning at age 85 years, based on analyses in community-dwelling men and women 65 years and older in four U.S. communities participating in the Cardiovascular Health Study. (From Fried et al. 1998; reprinted, with permission.) 
aging as a force for mortality, emerging independently of disease in the oldest old. Additionally, new research suggests that biologic aging can be characterized using population-based approaches as the composite of altered physiologic regulation and function across multiple systems. With this approach, longitudinally, young as well as older adults show differentiation between biologic and chronologic age, potentially as young as the mid-30s (Cohen et al. 2014; Belsky et al. 2015; Cohen et al. 2015).

\section{THE EMERGENCE OF FRAILTY IN OLDER AGE}

With increasing age, after about age 70, a new phenotype emerges, which is distinct from any single chronic disease and is an independent predictor of mortality in the short (3 yr) and intermediate $(7 \mathrm{yr})$ term: that of frailty. This phenotype (Table 1) meets the criteria for a medical syndrome (Fried et al. 2001; BandeenRoche et al. 2006; Morley et al. 2013). Criteria consist of a critical mass of three to five clinical components, including muscle weakness, slowed gait, low physical activity, sense of low energy or exhaustion, and unintentional weight loss. For $90 \%$ of those who become frail, frailty is chronic and progressive in its development (Xue 2011). Those with a subclinical presentation of only one or two components are at 2.5fold increased risk of progressing to having three to five components present in $3 \mathrm{yr}$ with full manifestation of the frailty phenotype (Fried et al. 2001). The prevalence of frailty increases with age after age 65 , and is twice as prevalent in women as men and African-Amer- icans as whites (Fried et al. 2001; Hirsch et al. 2006). By age $85, \sim 25 \%$ of older adults in the community manifest this phenotype; that is, they show three, four, or five components of frailty (Fried et al. 2001).

The characteristics of the phenotype were originally hypothesized to be a vicious cycle resulting from dysregulated energetics (Fig. 2). Such a cycle can be potentially initiated at any point, but the evidence is that in most older adults who become frail, it begins with declines in strength, walking speed, and/or physical activity and then progresses to also include selfreported low energy or exhaustion, and significant unintended weight loss (Xue 2011).

Notably, this phenotypic presentation has the characteristics of a medical syndrome: a constellation of symptoms and signs, when present in a critical mass, which predicts both characteristic outcomes and identifies a distinct underlying pathophysiology. The critical mass of criteria that are present have greater specificity for both outcomes and pathophysiology than any one or two factors (Fried et al. 2001; Bandeen-Roche et al. 2006). This constellation of factors has been shown to have the dynamics of a clinical syndrome in which there are no distinct subsets of criteria that cluster together, and any three (of five) factors that are present synergistically predict outcomes of mortality, disability onset and progression, hospitalization, falls, and nursing home admission, significantly more than any one or two factors (Bandeen-Roche et al. 2006). It has recently been recommended, in an international consensus conference, that frailty be considered a

Table 1. Criteria that define frailty ${ }^{\mathrm{a}}$

\begin{tabular}{ll}
\hline Characteristic & \multicolumn{1}{c}{ Criteria for frailty } \\
\hline Weight loss & Lost $>10$ pounds unintentionally last year \\
Exhaustion & Felt last week that "everything I did was an effort" or "I could not get going" \\
Slowness & Time to walk 15 feet (cutoff depends on sex and height) \\
Low activity level & $\begin{array}{c}\text { Expends }<270 \mathrm{kcal} / \text { week (calculated from activity scale incorporating episodes of walking, } \\
\text { household chores, yard work, etc.) }\end{array}$ \\
Weakness & $\begin{array}{c}\text { Grip strength measured using hand dynamometer (cutoff depends on sex and body mass } \\
\text { index [BMI]) }\end{array}$ \\
\hline
\end{tabular}

From Fried in press b; reprinted, with permission.

${ }^{a}$ Syndrome present when more than three characteristics are identified.

${ }^{\mathrm{b}}$ For specific measures and details for determining frailty criteria, see Fried et al. 2001. 
L.P. Fried
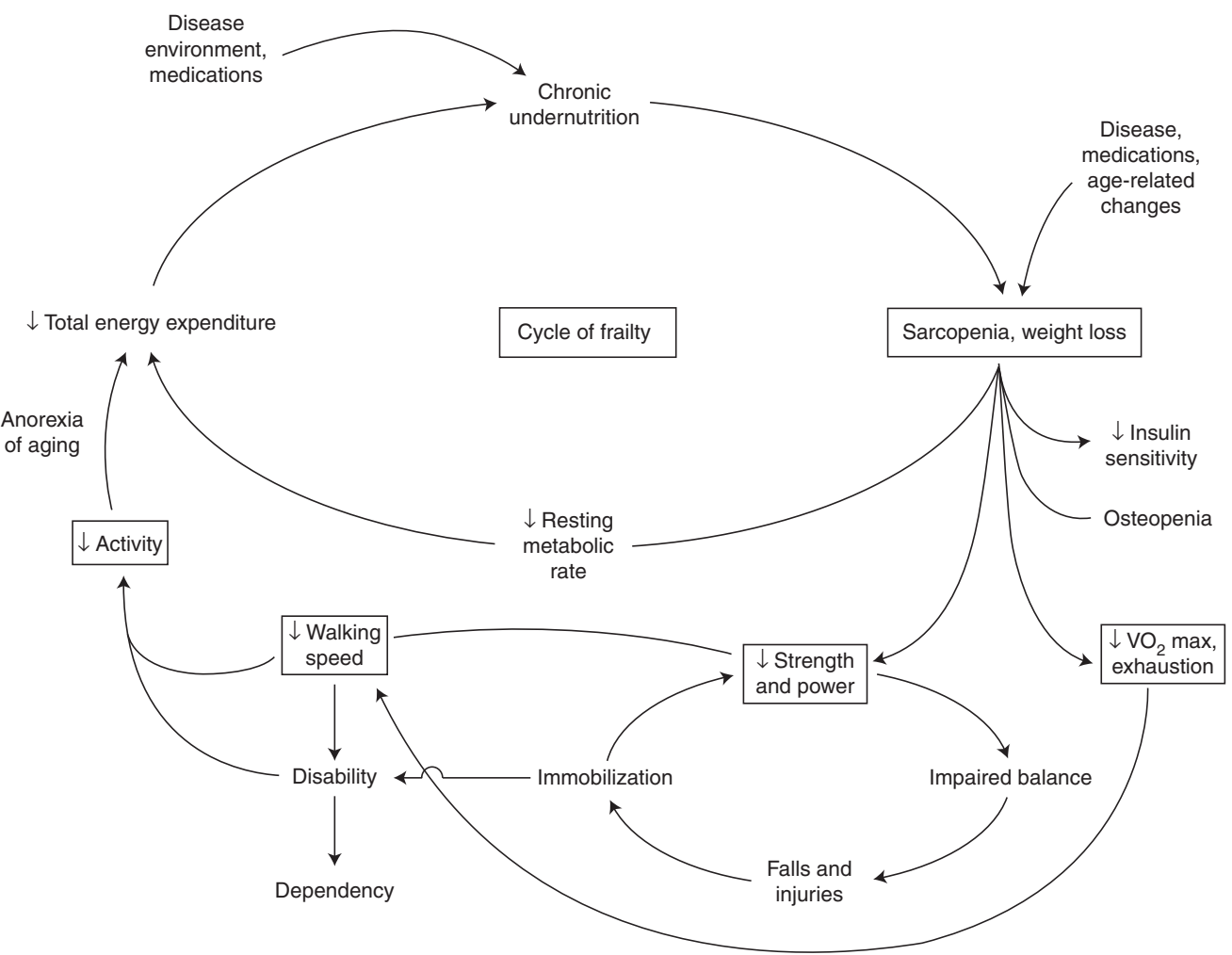

Figure 2. Vicious cycle of frailty in older adults. An expression of dysregulated energetics, evidence indicates that numerous exposures and chronic diseases, as well as aging-related processes, can initiate this cycle at any point. However, the early manifestations in the main are declines in muscle strength, walking speed, and/or physical activity, which predict development of exhaustion and—at end stages—significant unintentional weight loss. (From Fried et al. 2001; reprinted with permission.)

new medical syndrome (Morley et al. 2013) and that clinicians screen for frailty in people 70 and older as a basis for intervening to prevent or alleviate further decline.

\section{MECHANISMS UNDERLYING THE CLINICAL SYNDROME OF FRAILTY}

Consistent with the definition of a syndrome, the clinical presentation, or phenotype, identifies a specific etiologic pathophysiology. The extant evidence is briefly summarized here, considering both physiologic and biologic genesis.

First, there are a number of individual physiologic systems that have been identified as dysregulated in association with frailty. As background, there are many data that indicate declines with age in function of multiple func- tional and regulatory systems in the body, such as circulating levels of specific hormones (e.g., estrogens, testosterone, and insulin-like growth factor 1 [IGF-1]) (Kuchel et al. 2001), impaired insulin sensitivity (Davidson 1979; DeFronzo 1981; Shimokata et al. 1991; Scheen 2005; Metter et al. 2008), along with elevations of markers of inflammation (e.g., interleukin 6 [IL-6] and C-reactive protein $[\mathrm{CRP}]$ ) with aging (Ershler and Keller 2000; Reuben et al. 2002; Cohen et al. 2003; Joseph et al. 2005). Dynamic interactions between declines in gonadal hormones and increases in inflammatory mediators affect bone mass, as well as mobility (Cappola et al. 2003), whereas the impaired insulin sensitivity is predictive of both frailty and diabetes (Kalyani et al. 2012b). Notably, observations on insulin resistance indicate that, although this becomes ap- 
parent in the vast majority of women $>85$, frailty is associated with highest levels of dysregulation. For example, as exemplified for insulin resistance-homeostatic model assessment (IRHOMA) (Barzilay et al. 2007) or glycated hemoglobin (HgbA1C) (Kalyani et al. 2012b), an $\mathrm{HgbA} 1 \mathrm{C}$ of $6.5 \%$ and $8.0 \%$ or greater, respectively, are associated with frailty prevalence (Blaum et al. 2009) and threefold higher incidence (Kalyani et al. 2012b). In the latter study, the association of $\mathrm{HgbA1C}$ with frailty incidence is nonlinear. This suggests that the change in physiologic function with aging is associated with frailty past a threshold level of severity.

With this pattern in mind, I briefly summarize here the physiologic and biologic systems shown, to date, to be associated-when dysregulated-with the syndrome of frailty. For example, frail men and women 65 and older have lower muscle density and muscle mass and higher fat mass than do nonfrail persons (Cesari et al. 2006). Phenotypic frailty is also associated with altered resting metabolic rate (Weiss et al. 2012). Elevation of the following physiologic systems have been associated with the phenotype of frailty: elevated glucose and insulin in response to glucose tolerance test and elevated HgbA1C (Kalyani et al. 2012b), IR-HOMA, and inflammation (Walston et al. 2002; Barzilay et al. 2007); higher evening cortisol levels (Varadhan et al. 2008; Johar et al. 2014); elevated white blood cell counts (Baylis et al. 2013); and increased heart rate variability in association with frailty (Chaves et al. 2005). Along with the direct association between level of inflammation and frailty, there is an increase in frailty with the number of inflammatory diseases present (Chang et al. 2012).

Systems that are lower in association with frailty are: IGF-1, testosterone, didehydroepiandrosterone sulfate (DHEA-S), markers of clotting (Walston et al. 2002; Kalyani et al. 2012a), hemoglobin (Chaves et al. 2005), and serum carotenoid and micronutrient concentrations, with greater likelihood of multiple micronutrient deficiencies (Michelon et al. 2006). Low daily energy intake $(<21 \mathrm{kcal} / \mathrm{kg})$ is associated with $24 \%$ increased risk of frailty (Bartali et al. 2006). Low protein and vitamins D, C, and fo- late intakes are also associated with frailty, along with low intake of more than three nutrients.

Further, there is mounting evidence that biologic systems that are altered with aging also predict frailty. For example, building on the hypothesis that dysregulated energetics may underlie the development of frailty (Fried 2001), increasing attention is being focused on mitochondrial dysfunction. There is now strong evidence for such dysfunction with aging itself. The decline in mitochondrial function with aging limits production of adenosine triphosphate (ATP) (Chistiakov et al. 2014), which most prominently affects the function of tissues with high energy demand, for example, the nervous system, heart, and skeletal muscle. This has been shown to predict sarcopenia and loss of physical fitness and an increase in central obesity, diabetes, fatigue, and inflammation (Coen et al. 2013), all of which contribute to frailty. Now there is more specific implication of a mitochondrial genetic variant in frailty (Moore et al. 2010), and evidence that mitochondrial DNA (mtDNA) levels and number might form part of the biological component of the phenotype (Ashar et al. 2015). In separate studies, mtDNA copy number has been associated with ATP production rate (Short et al. 2005), and worsening in frailty status is associated with a significant decrease in global DNA methylation levels (Bellizzi et al. 2012). These findings support the theory that aging-associated decrease in mitochondrial function, with alterations in production of energy, might underlie both the phenotype and dysregulations of frailty.

Second, the whole is greater than the sum of the parts. It is clear that these individual systems are not independent of each other. For example, sarcopenia results, in part, both from hormonal deficiency and cytokine excess (Newman et al. 2001; Morley et al. 2005). Postmenopausal declines in serum estrogen and androgen levels contribute to increased bone loss (Joseph et al. 2005). Higher serum testosterone in older women is associated with insulin resistance (IR) and metabolic syndrome (Patel et al. 2009). Both IR and diabetes have been associated with excessive loss of lean body mass and 
L.P. Fried

muscle strength (Park et al. 2007, 2009). Further, IR is associated with skeletal muscle mitochondrial dysfunction (Phielix et al. 2008). Many physiological declines are mediated by proinflammatory cytokines, decline in hormones (especially, testosterone [T] and IGF$1)$, and IR; this has been well summarized by Morley et al. (2005). Further, inflammation is associated with lower leg muscle mass and strength, IR, frailty, and disability (Guralnik et al. 1994; Ferrucci et al. 2002; Visser et al. 2002; Hubbard et al. 2010).

With regard to frailty, prevalence and incidence of frailty is a product of the multiplicity of dysregulated systems, more than any one system. Overall, it has been shown that there is a nonlinear association of the number of systems dysregulated with frailty (Fried et al. 2009), and even within systems, the number of abnormal hormones (Cappola et al. 2003) or micronutrients (Semba et al. 2006) associated with frailty. Further, higher cortisol, DHEA-S ratio, as well as lower levels of DHEA-S and higher white blood cell counts predicted frailty over $10-y r$ follow-up, indicating interactions between the immune and endocrine axis (Baylis et al. 2013). One summary has stated that the "presence of decreased gonadal hormones and IGF-1, combined with unusually high peripheral levels of cytokines, inflammatory mediators, and coagulation markers all enhance risk of sarcopenia and frailty" (Joseph et al. 2005).
The nonlinear association of the number of systems dysregulated with the probability of frailty is consistent with frailty emerging from severe dysregulation of the complex dynamical system that maintains organismal homeostasis and resilience (Fried et al. 2009). As shown in Figure 3, there is a nonlinear increase in the prevalence of the phenotype of frailty as the number of abnormal physiologic systems increases in women 70-79 in the Women's Health and Aging Studies. The systems considered here include: hematological (hemoglobin $>12$ $\mathrm{mg} / \mathrm{dL}$ ); inflammatory (IL-6 top tertile); hormonal (deficiencies in IGF-1, DHEA-S, and HgbA1C); adiposity (lowest quartile, triceps skinfold thickness); neuromuscular (slow fine motor speed); and two or more micronutrients deficient. Further, the population subdivided into two classes: $70 \%$ with one or no systems abnormal, and 30\% with multiple systems (2.9, on average) abnormal; thus, three or more systems abnormal predict being frail. Notably, there were no dominating patterns of systems involved in association with frailty. However, the second class showed an odds ratio of 2.6 $(p<0.05)$ in association with being frail, adjusting for comorbid diseases, age, race, and education (Fried et al. 2009). Class 2 was associated with being frail after individually controlling for each of the eight systems, and none of the eight systems were individually significant except fine motor speed. Notably, the number

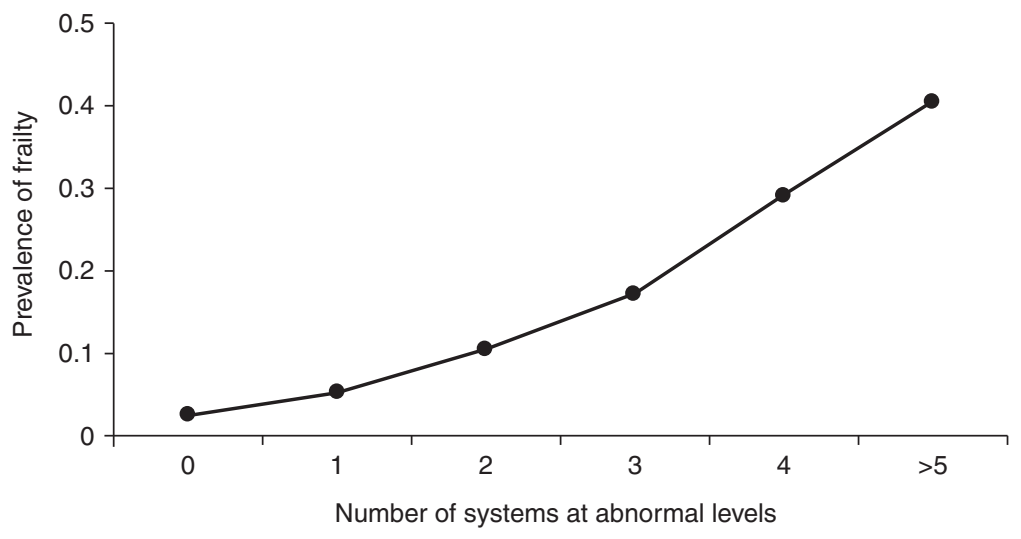

Figure 3. Association of number of physiological systems at abnormal levels with prevalence of being frail, women aged 70-79 ( $p<0.01$ for quantitative trend). (From Fried et al. 2009; reprinted, with permission.) 
of comorbid diseases was also associated with frailty, but independent of multisystem abnormalities; the strength of association approximated that of class 2. These findings support the biology underlying the phenotype of frailty as being that of a complex system, with the dominating predictor being the number of systems dysregulated, not any particular system.

The picture gets even more complex when one considers that the physiological systems implicated in frailty each affect two or more of the five components of the frailty phenotype and further mutually affect or regulate each other. The substantial network of physiologic connections implied here is consistent with the interconnected systems of feedforward and -back loops that are elements of a complex dynamical system. It has been suggested that the aggregate effect of senescent processes, such as those in the systems studied here, have a nonlinear contribution to a complex system (Yates 2002), even if their decline over the adult life course displays a quasilinear property individually. The findings summarized above are consistent with this theory, and with the concept of a complex adaptive system in which dysregulation of a threshold number of systems may culminate in critical loss of homeostatic adaptive capacity. This emergent property of frailty as the manifestation of a dysregulated complex adaptive system supports the concept of frailty as a biologically coherent behavior (Kitano 2002), and provides insight into reasons for the vulnerability of older adults who are in this emergent state of frailty to adverse health outcomes (e.g., death, falls, and disability). It is further supported by emerging work proposing underlying processes of alterations of networks of biomarkers with aging, with the decrements in whole networks predicting frailty (Cohen et al. 2015).

In summary, the phenotype of frailty appears to emerge in relation to latent, apparently etiologic, changes of increasing dysregulation of multiple physiologic systems. Frailty emerges when a threshold level of dysregulation develops. The severity of their individual and aggregate dysregulation predicts the severity of the phenotype, and both dysregulation and the emergence of the phenotype are age associated and predict mortality, but do not predict specific chronic diseases (Cohen et al. 2003, 2013, 2015). These changes involve, first and centrally, systems that mutually regulate homeostasis and response to stress and injury. Second, the findings are consistent with the dysregulation of a physiologic complex adaptive system, which is essential for resiliency (Fried et al. 2009).

Third, there is evidence that this dysregulated complex system is particularly manifest in the response to a challenge or stressor, and may well underlie the high risk of adverse outcomes in frailty. In a series of studies of response to an oral glucose tolerance test administered to 85- to 95-yr-old women in the Women's Health and Aging Study II, $>70 \%$ had compromised response to the glucose tolerance test; only $27 \%$ had a normal fasting glucose and normal oral glucose tolerance test (OGTT). However, those who were frail had a differentially worse response. Specifically, women who were frail had $67 \mathrm{mg} / \mathrm{dL}$ greater increase in glucose in response to OGTT, and markedly delayed return of glucose and insulin back to baseline, compared with those who were nonfrail or prefrail (Kalyani et al. 2012b).

Further, frail women showed abnormal hormonal stimulus-response dynamics in energy metabolism response after oral glucose load (Kalyani et al. 2012a), with a pattern of elevated glucose-raising hormones and decreased glucose-lowering hormones in the frail compared with the nonfrail. Overall, the findings suggested that frailty status may represent a threshold of dysregulation in energy metabolism hormones, particularly for ghrelin. These findings support the theory that the entire physiological network of hormones that mutually regulate glucose homeostasis are dysregulated in frailty. This further supports the line of reasoning that intrinsic homeostatic mechanisms to maintain energy balance may be blunted with aging (Wilson and Morley 2003).

Overall, these findings are consistent with frailty as a marker of a severe end stage of biologic aging, with underlying dysregulation of the complex dynamical systems that maintain a resilient organism, and in which dysregulation of the system will become evident in the pres- 
ence of stressors, with consequences, such as adverse health outcomes, which occur when the system is challenged. This theory is consistent with the basic tenets of biological complex systems (Csete and Doyle 2002; Kitano 2002). This complex system could well be considered a hallmark of aging, adding to the nine laid out by López-Otín et al. (2013).

\section{IMPLICATIONS OF FRAILTY AS A DYSREGULATED COMPLEX SYSTEM FOR THERAPEUTIC OR PREVENTIVE APPROACH}

Ultimately, the evidence of frailty as a complex system suggests why interventions targeting only one of many dysregulated systems, such as hormonal supplementation, have not been found to prevent or ameliorate frail states.

For example, many trials of monotherapies, such as replacement of estrogen or testosterone (Snyder et al. 1999; Taaffe et al. 2005; Ronkainen et al 2009; Kenny et al. 2010), for mitigation of frailty have not been successful. There are many other dimensions that need to be understood beyond this; for example, why is it that estrogen-replacement therapy does not protect against skeletal muscle loss with aging in women, whereas testosterone does predict muscle mass (Kenny et al. 2003)? With these observations as background, for the rest of this article we focus on the evidence of frailty as a complex system problem as the basis for a differential approach to prevention or treatment.

A particular focus to intervention within this framework could be the role of energy dysregulation as a critical entry point to development of frailty. Certainly, across the evidence summarized above, there are key elements of energy dysregulation now identified as components or drivers of frailty, from the altered energy intake in diet, to the phenotype itself, including unintentional weight loss, physical exhaustion and sarcopenia, and muscle weakness (Fig. 2) (Fried et al.2001), to altered glucose metabolism and muscle efficiency, to mitochondrial function. Considering the evidence, this would suggest that therapeutic opportunities need to focus on improving energy production and use, and shifting the entire complex system of function.

\section{PHYSICAL ACTIVITY AS A MODEL FOR INTERVENTIONS THAT MIGHT PREVENT, DELAY, OR TREAT FRAILTY}

Physical activity, as an intervention, offers an intriguing model for the type of intervention that could prevent or mitigate frailty. This article concludes by offering the reasoning for this statement.

First, if one considers the association of physical activity with frailty, declines in physical activity both predict, early on, the development of the rest of the phenotype (Xue et al. 2012) and likely exacerbate both frailty-related outcomes and the underlying dysregulation. Consider in terms of outcomes that, although frailty has been shown to predict mortality, falls, and disability more powerfully than physical activity alone, low levels of physical activity, into the oldest ages, independently predict these outcomes, including mortality (Kushi et al 1997; Fried et al. 1998; Andersen et al. 2000; Katzmarzyk et al. 2003; Hu et al. 2004). Physical activity is consistently a predictor of lower mortality, as well as of greater muscle strength, into the oldest ages. In observational studies of older adults, for example, Xue et al. (2012) has shown in a 12-yr follow-up of women 70-79 at baseline in the Women's Health and Aging Study II, that those who rapidly declined in physical activity over 12 yr or who were always sedentary (adjusting for chronic diseases, disability, obesity, and other confounders) had hazard ratios for death of 2.34 and 3.34, compared with those who were always active. Further, the findings suggested that physical activity did not have to be vigorous to have benefit (Xue et al. 2012).

Second, physical activity is known to preserve or improve the function of many of the physiologic systems at abnormal levels in frail older adults: for example, sarcopenia and protein synthesis (Zampieri et al. 2015), muscle force and function, and fiber morphology. Gómez-Cabello et al. (2014) showed that, in people 65 and older, physical activity in women was associated with both upper and lower body strength, whereas in men it was associated with strength of knee and grip. Further, exercise maintains or improves glucose metabolism, in- 
flammation, and anemia, as well as exercise tolerance underlying the feeling of "exhaustion" or low energy in the phenotype.

Third, declines in energy availability to the individual because of impairment in ATP production with aging may depend on mitochondrial dysfunction (Trounce et al. 1989; Shigenaga et al. 1994), which itself is partially corrected by physical activity. Exercise has been shown to maintain mitochondrial function in aging and prevent release of reactive oxygen species (ROS). Regular exercise over adulthood not only preserves muscle force, function, and morphology, but preserves ultrastructure of intracellular organelles involved in calcium handling and ATP production, and lowers expression of genes related to autophagy and ROS detoxification, important for clearance of damaged organelles and proteins. Conversely, inactive aging results in drastic reduction in number of calcium release units and volume and number of mitochondria in muscle, compared with young individuals (Zampieri et al. 2015), as well as structure and preservation of organelle positioning — all dimensions that could directly influence ATP production and, thus, be important for overall muscle performance (Zampieri et al. 2015).

Notably, it appears possible to maintain a tuned energetics system with maintenance of physical activity over the life course and into the oldest ages. As reported by Zampieri et al. (2015), skeletal muscle of well-trained seniors with a 30-year history of regular exercise is more like that of young adults than that of agematched sedentary individuals, and signaling pathways controlling muscle mass and metabolism are differently modulated in senior sportsmen to support maintenance of skeletal muscle structure (preservation of slow-type fibers), function, bioenergetics characteristics (improved oxidative muscle metabolism), and phenotype. The general organization of the metabolic apparatus is far better preserved in individuals who exercised regularly. For example, the frequency of mitochondria is higher in athletic than sedentary seniors, with mitochondria being even more positively affected than the excitation-contraction coupling apparatus. Zam- pieri et al. (2015) have shown that the frequency of calcium release unit (CRU)-mitochondrial pairs is threefold higher in senior sportsmen; this functional coupling up-regulates ATP production when muscle is active (Brookes et al 2004; Shkryl and Shirokova 2006; Mosole et al. 2014). Notably, there is also significant up-regulation of miR-206 expression in senior sportsmen, compared with young adults and healthy sedentary seniors; this microRNA has been shown to play a specific role in the early events of regeneration (Cacchiarelli et al. 2010). Conversely, autophagy-related genes were significantly up-regulated in sedentary seniors compared with age-matched senior sportsmen and young adults. This suggests that signaling pathways that control muscle mass and metabolism are differently modulated in senior sportsmen to preserve bioenergetics characteristics and morphology, and that regular physical activity can now be seen as "a good strategy to attenuate agerelated general decay of muscle structure and function" (Zampieri et al. 2015). Supporting this, as one outcome measure, the Health ABC study found in older participants followed for $5 \mathrm{yr}$ that sedentary individuals had significantly increased risk of decline in gait speed to $<0.60$ $\mathrm{m} / \mathrm{sec}$ and/or inability to rise from a chair without use of arms (Peterson et al. 2009) compared with those who actively exercised. This suggests that self-selected exercise activities may be independently associated with delaying onset and progression of frailty (Peterson et al. 2009).

Zampieri's conclusion was that "a specific, well-directed program of training could improve body balance, muscle structure, and contractile properties in elderly persons" (Zampieri et al. 2015). In fact, exercise trials of different intensities in older adults of different degrees of frailty have shown the benefit. Notably, one of the first studies in this arena was that by Fiatarone et al. (1990), which showed an almost twofold improvement of nonagenarian muscle strength and balance by a weight-lifting protocol. More recently, the LIFE Study randomized controlled trial showed that, among adults 7089 at risk for disability (defined as sedentary, SPPB 9 or lower; could walk $400 \mathrm{~m}$ in $<15$ min; no major cognitive impairment), a struc- 


\section{L.P. Fried}

tured, moderate intensity physical activity program that included aerobic (150 min per week of walking, with a goal of $30 \mathrm{~min}$ daily at intensity of 13), plus resistance and flexibility and balance training activities (compared with health education program) led to a significant difference in frailty prevalence at $12 \mathrm{mo}(10 \%)$ compared with successful aging group (19\%), and the mean number of frailty criteria was especially reduced for younger subjects, Blacks, participants with frailty, and those with multimorbidity (Pahor et al. 2014; Cesari et al. 2015).

\section{IMPLICATIONS}

Thus, trials of physical activity suggest that this offers a low-risk and effective preventive and therapeutic intervention to prevent or mitigate frailty. These findings are important in themselves. However, they offer intriguing implications in terms of criteria for other therapies to be considered in the future. These implications draw directly from further evidence, that physical activity "tunes" - or improves the function - of many systems in the body that are implicated in frailty etiology, as discussed above. These include muscle structure and function, hormonal, inflammatory, immune, hematologic, and other coregulatory functions, as well as supporting improved brain functions. Evidence ranges from trials of aerobic exercise training (for 6-9 mo), which showed improved heart rate variability in older adults (Levy et al. 1998; Schuit et al. 1999; Stein et al. 1999; Lipsitz 2002), to the metformin trial, which showed that the lifestyle intervention (with at least 150 min of physical activity per week) was more effective in restoring normal postload glucose values than was metformin or placebo, with the advantage of the lifestyle intervention being greater in older individuals (Nathan 2002), to the work of Lindholm et al. (2014); indicating

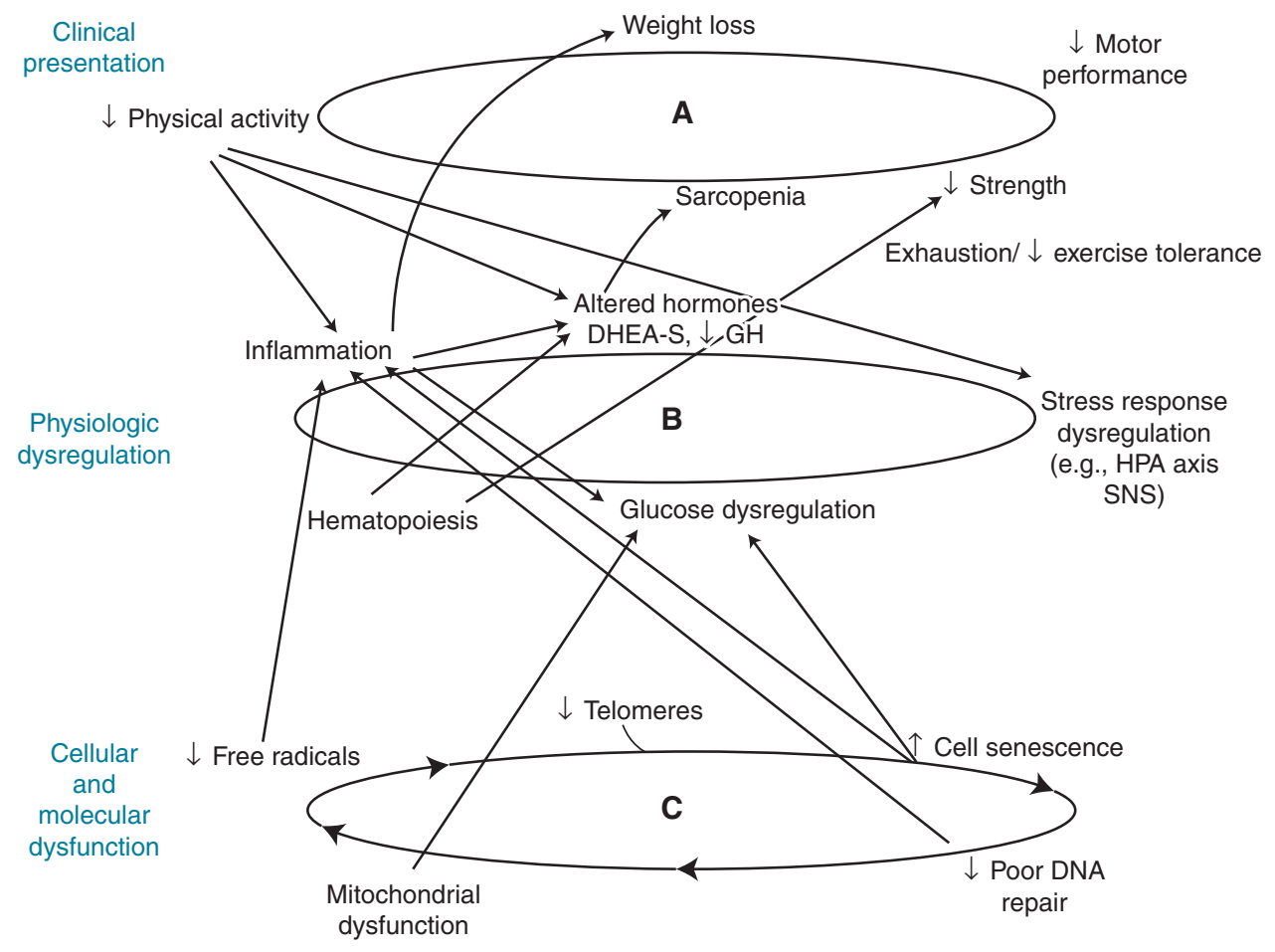

Figure 4. Physical activity positively affects function of multiple components of the syndrome of frailty at levels of $(A)$ frailty phenotype, $(B)$ physiologic dysregulation, and $(C)$ cellular function. DHEA-S, didehydroepiandrosterone sulfate; GH, growth hormone; HPA, hypothalamic-pituitary-adrenal; SNS, sympathetic nervous system. 
that exercise of one leg in human volunteers leads to leg-specific epigenetic benefits in muscle: in addition to increased mass, epigenetic benefits, including new methylation patterns in $>5000$ sites on genome of muscle cells, particularly affected many muscle enhancers in genome that amplify expression of proteins by genes. Most of the genes affected play a role in energy metabolism, insulin response, and inflammation in muscles.

Further, exercise offers an intriguing model of a single intervention with multisystem benefits (Fig. 4). This confers great efficiency, but it also offers a model for types of interventions that may be effective in frailty as the outcome of dysregulation of the well-tuned complex dynamical system of a resilient organism. This is because physical activity simultaneously upregulates many systems that mutually regulate each other in combination. Thus, the whole organism could be retuned to a higher functional level. This offers a model intervention that matches well a complex system problem. If monotherapies are not sufficient, then finding an intervention that "tunes" a critical mass of systems would be critical. Kitano (2007) has asserted that frailty is the consequence of a trade-off between robustness and fragility ( $\mathrm{Ki}^{-}$ tano 2007), with robustness contributing to homeostasis and maintenance of functionality. Bortz (2008) has further stated that "Frailty is an assertion of the loss of dynamics, body-wise and system-wide" and that "It is in the tuning of the entire orchestra of genes to the cueing ' $A$ ' of the oboe where health resides." Physical activity offers both the first evidence as to effective approaches to preventing or treating frailty and a biologic model for future therapies.

\section{REFERENCES}

Andersen LB, Schnohr P, Schroll M, Hein HO. 2000. Allcause mortality associated with physical activity during leisure time, work, sports, and cycling to work. Arch Intern Med 160: 1621-1628.

Ashar F, Moes A, Moore A, Grove M, Chaves PM, Coresh J Newman A, Matteini A, Bandeen-Roche K, Boerwinkle E, et al. 2015. Association of mitochondrial DNA levels with frailty and all-cause mortality. J Mol Med 93: 177-186.
Bandeen-Roche K, Xue QL, Ferrucci L, Walston J, Guralnik JM, Chaves P, Zeger SL, Fried LP. 2006. Phenotype of frailty: Characterization in the women's health and aging studies. J Gerontol A Biol Sci Med Sci 61: 262-266.

Bartali B, Frongillo EA, Bandinelli S, Lauretani F, Semba RD, Fried LP, Ferrucci L. 2006. Low nutrient intake is an essential component of frailty in older persons. J Gerontol A Biol Sci Med Sci 61: 589-593.

Barzilay JI, Blaum C, Moore T, Xue QL, Hirsch CH, Walston JD, Fried LP. 2007. Insulin resistance and inflammation as precursors of frailty: The Cardiovascular Health Study. Arch Intern Med 167: 635-641.

Baylis D, Bartlett DB, Syddall HE, Ntani G, Gale CR, Cooper C, Lord JM, Sayer AA. 2013. Immune-endocrine biomarkers as predictors of frailty and mortality: A 10-year longitudinal study in community-dwelling older people. Age (Dordr) 35: 963-971.

Bellizzi D, D’Aquila P, Montesanto A, Corsonello A, Mari V, Mazzei B, Lattanzio F, Passarino G. 2012. Global DNA methylation in old subjects is correlated with frailty. Age (Dordr) 34: 169-179.

Belsky DW, Caspi A, Houts R, Cohen HJ, Corcoran DL, Danese A, Harrington H, Israel S, Levine ME, Schaefer JD, et al. 2015. Quantification of biological aging in young adults. Proc Natl Acad Sci 112: E4104-E4110.

Blaum CS, Xue QL, Tian J, Semba RD, Fried LP, Walston J. 2009. Is hyperglycemia associated with frailty status in older women? J Am Geriatr Soc 57: 840-847.

Bortz WM. 1993. The physics of frailty. JAm Geriatr Soc 41: 1004-1008.

Bortz WM. 2008. Frailty. Mech Ageing Dev 129: 680.

Brookes PS, Yoon Y, Robotham JL, Anders MW, Sheu SS. 2004. Calcium, ATP, and ROS: A mitochondrial lovehate triangle. Am J Physiol Cell Physiol 287: C817-C833.

Cacchiarelli D, Martone J, Girardi E, Cesana M, Incitti T, Morlando M, Nicoletti C, Santini T, Sthandier O, Barberi L, et al. 2010. MicroRNAs involved in molecular circuitries relevant for the Duchenne muscular dystrophy pathogenesis are controlled by the dystrophin/nNOS pathway. Cell Metab 12: 341-351.

Cappola AR, Xue QL, Ferrucci L, Guralnik JM, Volpato S, Fried LP. 2003. Insulin-like growth factor I and Interleukin-6 contribute synergistically to disability and mortality in older women. J Clin Endocrinol Metab 88: 20192025 .

Cesari M, Leeuwenburgh C, Lauretani F, Onder G, Bandinelli S, Maraldi C, Guralnik JM, Pahor M, Ferrucci L. 2006. Frailty syndrome and skeletal muscle: Results from the Invecchiare in Chianti study. Am J Clin Nutr 83: $1142-1148$.

Cesari M, Vellas B, Hsu FC, Newman AB, Doss H, King AC, Manini TM, Church T, Gill TM, Miller ME, et al. 2015. A physical activity intervention to treat the frailty syndrome in older persons-Results from the LIFE-P study. J Gerontol A Biol Sci Med Sci 70: 216-222.

Chang SS, Weiss CO, Xue QL, Fried LP. 2012. Association between inflammatory-related disease burden and frailty: Results from the Women's Health and Aging Studies (WHAS) I and II. Arch Gerontol Geriatr 54: 9-15.

Chaves PHM, Semba RD, Leng SX, Woodman RC, Ferrucci L, Guralnik JM, Fried LP. 2005. Impact of anemia and 


\section{L.P. Fried}

cardiovascular disease on frailty status of communitydwelling older women: The Women's Health and Aging Studies I and II. J Gerontol A Biol Sci Med Sci 60: 729735.

Chistiakov DA, Sobenin IA, Revin VV, Orekhov AN, Bobryshev YV. 2014. Mitochondrial aging and age-related dysfunction of mitochondria. Biomed Res Int 2014: 238463

Coen PM, Jubrias SA, Distefano G, Amati F, Mackey DC, Glynn NW, Manini TM, Wohlgemuth SE, Leeuwenburgh C, Cummings SR. 2013. Skeletal muscle mitochondrial energetics are associated with maximal aerobic capacity and walking speed in older adults. J Gerontol A Biol Sci Med Sci 68: 447-455.

Cohen HJ, Harris T, Pieper CF. 2003. Coagulation and activation of inflammatory pathways in the development of functional decline and mortality in the elderly. Am J Med 114: $180-187$.

Cohen AA, Milot E, Yong J, Seplaki CL, Fulop T, BandeenRoche K, Fried LP. 2013. A novel statistical approach shows evidence for multi-system physiological dysregulation during aging. Mech Ageing Dev 134: 110-117.

Cohen AA, Milot E, Li Q, Legault V, Fried LP, Ferrucci L. 2014. Cross-population validation of statistical distance as a measure of physiological dysregulation during aging. Exp Gerontol 57: 203-210.

Cohen AA, Milot E, Li Q, Bergeron P, Poirier R, DusseaultBélanger F, Fülöp T, Leroux M, Legault V, Metter EJ. 2015. Detection of a novel, integrative aging process suggests complex physiological integration. PloS ONE 10: e0116489.

Csete ME, Doyle JC. 2002. Reverse engineering of biological complexity. Science 295: 1664-1669.

Davidson MB. 1979. The effect of aging on carbohydrate metabolism: A review of the English literature and a practical approach to the diagnosis of diabetes mellitus in the elderly. Metabolism 28: 688-705.

DeFronzo RA. 1981. Glucose intolerance and aging. Diabetes Care 4: 493-501.

Ershler WB, Keller ET. 2000. Age-associated increased interleukin-6 gene expression, late-life diseases, and frailty. Annu Rev Med 51: 245-270.

Ferrucci L, Penninx BW, Volpato S, Harris TB, BandeenRoche K, Balfour J, Leveille SG, Fried LP, Md JM. 2002. Change in muscle strength explains accelerated decline of physical function in older women with high interleukin6 serum levels. J Am Geriatr Soc 50: 1947-1954.

Fiatarone MA, Marks EC, Ryan ND, Meredith CN, Lipsitz LA, Evans WJ. 1990. High-intensity strength training in nonagenarians: Effects on skeletal muscle. JAMA 263: 3029-3034.

Fried LP. Global report on aging and health. World Health Organization, Geneva (in press a).

Fried LP. Frailty. In Geriatrics review syllabus: A core curriculum in geriatric medicine, 9th ed. (ed. Medina-Walpole A, et al.). American Geriatrics Society, New York (in press b).

Fried LP, Ferrucci L. Etiological role of aging in chronic diseases: From epidemiological evidence to the new geroscience, Chap. 2. In Advances in geroscience (ed. Sierra F, Kohanski RA). Springer, New York (in press).

Fried LP, Kronmal RA, Newman AB, Bild DE, Mittelmark MB, Polak JF, Robbins JA, Gardin JM. 1998. Risk factors for 5-year mortality in older adults: The Cardiovascular Health Study. JAMA 279: 585-592.

Fried LP, Tangen CM, Walston J, Newman AB, Hirsch C Gottdiener J, Seeman T, Tracy R, Kop WJ, Burke G, et al. 2001. Frailty in older adults: Evidence for a phenotype. J Gerontol A Biol Sci Med Sci 56: M146-M156.

Fried LP, Xue QL, Cappola AR, Ferrucci L, Chaves P, Varadhan R, Guralnik JM, Leng SX, Semba RD, Walston JD. 2009. Nonlinear multisystem physiological dysregulation associated with frailty in older women: Implications for etiology and treatment. J Gerontol A Biol Sci Med Sci 64: 1049-1057.

Fries J. 2001. Aging, cumulative disability, and the compression of morbidity. Compr Ther 27: 322-329.

Geronimus AT, Pearson JA, Linnenbringer E, Schulz AJ, Reyes AG, Epel ES, Lin J, Blackburn EH. 2015. Race-ethnicity, poverty, urban stressors, and telomere length in a Detroit community-based sample. J Health Soc Behav 56: 199-224.

Gómez-Cabello A, Carnicero JA, Alonso-Bouzón C, Tresguerres JÁ, Alfaro-Acha A, Ara I, Rodriguez-Mañas L, García-García FJ. 2014. Age and gender, two key factors in the associations between physical activity and strength during the ageing process. Maturitas 78: 106-112.

Green DR, Galluzzi L, Kroemer G. 2011. Mitochondria and the autophagy-inflammation-cell death axis in organismal aging. Science 333: 1109-1112.

Guralnik JM, Simonsick EM, Ferrucci L, Glynn RJ, Berkman LF, Blazer DG, Scherr PA, Wallace RB. 1994. A short physical performance battery assessing lower extremity function: Association with self-reported disability and prediction of mortality and nursing home admission. $J$ Gerontol 49: M85-M94.

Hirsch C, Anderson ML, Newman A, Kop W, Jackson S, Gottdiener J, Tracy R, Fried LP. 2006. The association of race with frailty: The cardiovascular health study. Ann Epidemiol 16: 545-553.

Hu FB, Willett WC, Li T, Stampfer MJ, Colditz GA, Manson JE. 2004. Adiposity as compared with physical activity in predicting mortality among women. $N$ Engl J Med 351: 2694-2703.

Hubbard RE, Lang IA, Llewellyn DJ, Rockwood K. 2010. Frailty, body mass index, and abdominal obesity in older people. J Gerontol A Biol Sci Med Sci 65: 377-381.

Johar H, Emeny RT, Bidlingmaier M, Reincke M, Thorand B, Peters A, Heier M, Ladwig KH. 2014. Blunted diurnal cortisol pattern is associated with frailty: A cross-sectional study of 745 participants aged 65 to 90 years. J Clin Endocrinol Metab 99: E464-E468.

Joseph C, Kenny AM, Taxel P, Lorenzo JA, Duque G, Kuchel GA. 2005. Role of endocrine-immune dysregulation in osteoporosis, sarcopenia, frailty and fracture risk. $\mathrm{Mol}$ Aspects Med 26: 181-201.

Kalyani R, Varadhan R, Weiss CO, Fried LP, Cappola AR. 2012a. Frailty status and altered dynamics of circulating energy metabolism hormones after oral glucose in older women. J Nutr Health Aging 16: 679-686.

Kalyani RR, Tian J, Xue QL, Walston J, Cappola AR, Fried LP, Brancati FL, Blaum CS. 2012b. Hyperglycemia and incidence of frailty and lower extremity mobility limitations in older women. J Am Geriatr Soc 60: 1701-1707. 
Kalyani RR, Varadhan R, Weiss CO, Fried LP, Cappola AR. 2012c. Frailty status and altered glucose-insulin dynamics. J Gerontol A Biol Sci Med Sci 67: 1300-1306.

Katzmarzyk PT, Janssen I, Ardern CI. 2003. Physical inactivity, excess adiposity and premature mortality. Obes Rev 4: $257-290$.

Kenny AM, Dawson L, Kleppinger A, Iannuzzi-Sucich M, Judge JO. 2003. Prevalence of sarcopenia and predictors of skeletal muscle mass in nonobese women who are long-term users of estrogen-replacement therapy. J Gerontol A Biol Sci Med Sci 58: M436-M440.

Kenny AM, Kleppinger A, Annis K, Rathier M, Browner B, Judge JO, McGee D. 2010. Effects of transdermal testosterone on bone and muscle in older men with low bioavailable testosterone levels, low bone mass, and physical frailty. J Am Geriatr Soc 58: 1134-1143.

Kern H, Pelosi L, Coletto L, Musarò A, Sandri M, Vogelauer M, Trimmel L, Cvecka J, Hamar D, Kovarik J, et al. 2011. Atrophy/hypertrophy cell signaling in muscles of young athletes trained with vibrational-proprioceptive stimulation. Neurol Res 33: 998-1009.

Kitano H. 2002. Computational systems biology. Nature 420: 206-210.

Kitano H. 2007. Towards a theory of biological robustness. Mol Syst Biol 3: 137.

Kobrosly RW, van Wijngaarden E, Seplaki CL, Cory-Slechta DA, Moynihan J. 2014. Depressive symptoms are associated with allostatic load among community-dwelling older adults. Physiol Behav 123: 223-230.

Kuchel GA, Tannenbaum C, Greenspan SL, Resnick NM. 2001. Can variability in the hormonal status of elderly women assist in the decision to administer estrogens? J Womens Health Gend Based Med 10: 109-116.

Kushi LH, Fee RM, Folsom AR, Mink PJ, Anderson KE, Sellers TA. 1997. Physical activity and mortality in postmenopausal women. JAMA 277: 1287-1292.

Levine ME, Crimmins EM. 2014. Evidence of accelerated aging among African Americans and its implications for mortality. Soc Sci Med 118: 27-32.

Levy WC, Cerqueira MD, Harp GD, Johannessen KA, Abrass IB, Schwartz RS, Stratton JR. 1998. Effect of endurance exercise training on heart rate variability at rest in healthy young and older men. Am J Cardiol 82: 1236-1241.

Lindholm ME, Marabita F, Gomez-Cabrero D, Rundqvist H, Ekström TJ, Tegnér J, Sundberg CJ. 2014. An integrative analysis reveals coordinated reprogramming of the epigenome and the transcriptome in human skeletal muscle after training. Epigenetics 9: 1557-1569.

Lipsitz LA. 2002. Dynamics of stability: The physiologic basis of functional health and frailty. J Gerontol A Bio Sci Med Sci 57: B115-B125.

López-Otín C, Blasco MA, Partridge L, Serrano M, Kroemer G. 2013. The hallmarks of aging. Cell 153: 1194-1217.

Metter EJ, Windham BG, Maggio M, Simonsick EM, Ling SM, Egan JM, Ferrucci L. 2008. Glucose and insulin measurements from the oral glucose tolerance test and mortality prediction. Diabetes Care 31: 1026-1030.

Michelon E, Blaum C, Semba RD, Xue QL, Ricks MO, Fried LP. 2006. Vitamin and carotenoid status in older women: Associations with the frailty syndrome. J Gerontol A Biol Sci Med Sci 61: 600-607.
Moore AZ, Biggs ML, Matteini A, O'Connor A, McGuire S, Beamer BA, Fallin MD, Fried LP, Walston J, Chakravarti A, et al. 2010. Polymorphisms in the mitochondrial DNA control region and frailty in older adults. PLOS ONE 5: e11069.

Morley JE, Kim MJ, Haren MT, Kevorkian R, Banks WA. 2005. Frailty and the aging male. Aging Male 8: 135-140.

Morley JE, Vellas B, Abellan van Kan G, Anker SD, Bauer JM, Bernabei R, Cesari M, Chumlea WC, Doehner W, Evans J, et al. 2013. Frailty consensus: A call to action. J Am Med Dir Assoc 14: 392-397.

Mosole S, Carraro U, Kern H, Loefler S, Fruhmann H, Vogelauer M, Burggraf S, Mayr W, Krenn M, PaternostroSluga T. 2014. Long-term high-level exercise promotes muscle reinnervation with age. J Neuropathol Exp Neurol 73: $284-294$.

Musarò A, McCullagh K, Paul A, Houghton L, Dobrowolny G, Molinaro M, Barton ER, Sweeney HL, Rosenthal N. 2001. Localized Igf-1 transgene expression sustains hypertrophy and regeneration in senescent skeletal muscle. Nat Genet 27: 195-200.

Musarò A, Giacinti C, Dobrowolny G, Pelosi L, Rosenthal N. 2004. The role of IGF-I on muscle wasting: A therapeutic approach. Basic Appl Myol 14: 29-33.

Nathan DM. 2002. Initial management of glycemia in type 2 diabetes mellitus. N Engl J Med 347: 1342-1349.

Newman AB, Gottdiener JS, McBurnie MA, Hirsch CH, Kop WJ, Tracy R, Walston JD, Fried LP. 2001. Associations of subclinical cardiovascular disease with frailty. J Gerontol A Biol Sci Med Sci 56: M158-M166.

Nicklett EJ, Semba RD, Xue QL, Tian J, Sun K, Cappola AR, Simonsick EM, Ferrucci L, Fried LP. 2012. Fruit and vegetable intake, physical activity, and mortality in older community-dwelling women. J Am Geriatr Soc 60: $862-868$.

Pahor M, Guralnik JM, Ambrosius WT, Blair S, Bonds DE, Church TS, Espeland MA, Fielding RA, Gill TM, Groessl EJ, et al. 2014. Effect of structured physical activity on prevention of major mobility disability in older adults: The life study randomized clinical trial. JAMA 311: 2387-2396.

Park SW, Goodpaster BH, Strotmeyer ES, Kuller LH, Broudeau R, Kammerer C, de Rekeneire N, Harris TB, Schwartz AV, Tylavsky FA, et al. 2007. Accelerated loss of skeletal muscle strength in older adults with type 2 diabetes: The health, aging, and body composition study. Diabetes Care 30: 1507-1512.

Park SW, Goodpaster BH, Lee JS, Kuller LH, Boudreau R, de Rekeneire N, Harris TB, Kritchevsky S, Tylavsky FA, Nevitt $M$, et al. 2009. Excessive loss of skeletal muscle mass in older adults with type 2 diabetes. Diabetes Care 32: 1993-1997.

Patel SM, Ratcliffe SJ, Reilly MP, Weinstein R, Bhasin S, Blackman MR, Cauley JA, Sutton-Tyrrell K, Robbins J, Fried LP, et al. 2009. Higher serum testosterone concentration in older women is associated with insulin resistance, metabolic syndrome, and cardiovascular disease. $J$ Clin Endocrinol Metab 94: 4776-4784.

Pelosi L, Giacinti C, Nardis C, Borsellino G, Rizzuto E, Nicoletti C, Wannenes F, Battistini L, Rosenthal N, Molinaro M, et al. 2007. Local expression of IGF-1 accelerates 
L.P. Fried

muscle regeneration by rapidly modulating inflammatory cytokines and chemokines. FASEB J 21: 1393-1402.

Peterson MJ, Giuliani C, Morey MC, Pieper CF, Evenson KR, Mercer V, Cohen HJ, Visser M, Brach JS, Kritchevsky SB, et al. 2009. Physical activity as a preventative factor for frailty: The health, aging, and body composition study. $J$ Gerontol A Biol Sci Med Sci 64A: 61-68.

Phielix E, Schrauwen-Hinderling VB, Mensink M, Lenaers E, Meex R, Hoeks J, Kooi ME, Moonen-Kornips E, Sels JP, Hesselink MK, et al. 2008. Lower intrinsic ADP-stimulated mitochondrial respiration underlies in vivo mitochondrial dysfunction in muscle of male type 2 diabetic patients. Diabetes 57: 2943-2949.

Reuben DB, Cheh AI, Harris TB, Ferrucci L, Rowe JW, Tracy RP, Seeman TE. 2002. Peripheral blood markers of inflammation predict mortality and functional decline in high-functioning community-dwelling older persons. J Am Geriatr Soc 50: 638-644.

Ronkainen PH, Kovanen V, Alen M, Pöllänen E, Palonen EM, Ankarberg-Lindgren C, Hämäläinen E, Turpeinen U, Kujala UM, Puolakka J. 2009. Postmenopausal hormone replacement therapy modifies skeletal muscle composition and function: A study with monozygotic twin pairs. J Appl Physiol 107: 25-33.

Scheen AJ. 2005. Diabetes mellitus in the elderly: Insulin resistance and/or impaired insulin secretion? Diabetes Metab 31: 5S27-25S34.

Schuit AJ, van Amelsvoort LG, Verheij TC, Rijneke RD, Maan AC, Swenne CA, Schouten EG. 1999. Exercise training and heart rate variability in older people. Med Sci Sports Exerc 31: 816-821.

Semba RD, Bartali B, Zhou J, Blaum C, Ko CW, Fried LP. 2006. Low serum micronutrient concentrations predict frailty among older women living in the community. $J$ Gerontol A Biol Sci Med Sci 61: 594-599.

Shigenaga MK, Hagen TM, Ames BN. 1994. Oxidative damage and mitochondrial decay in aging. Proc Natl Acad Sci 91: 10771-10778.

Shimokata H, Muller DC, Fleg JL, Sorkin J, Ziemba AW, Andres R. 1991. Age as independent determinant of glucose tolerance. Diabetes 40: 44-51.

Shkryl VM, Shirokova N. 2006. Transfer and tunneling of $\mathrm{Ca}^{2+}$ from sarcoplasmic reticulum to mitochondria in skeletal muscle. J Biol Chem 281: 1547-1554.

Short KR, Bigelow ML, Kahl J, Singh R, Coenen-Schimke J, Raghavakaimal S, Nair KS. 2005. Decline in skeletal muscle mitochondrial function with aging in humans. Proc Natl Acad Sci 102: 5618-5623.

Snyder PJ, Peachey H, Hannoush P, Berlin JA, Loh L, Lenrow DA, Holmes JH, Dlewati A, Santanna J, Rosen CJ, et al. 1999. Effect of testosterone treatment on body composition and muscle strength in men over 65 years of age. $J$ Clin Endocrinol Metab 84: 2647-2653.

Stein PK, Ehsani AA, Domitrovich PP, Kleiger RE, Rottman JN. 1999. Effect of exercise training on heart rate variability in healthy older adults. Am Heart $J$ 138: 567-576.
Szanton S, Allen J, Seplaki C, Bandeen-Roche K, Fried L. 2009. Allostatic load and frailty in the women's health and aging studies. Biol Res Nurs 10: 248-256.

Taaffe DR, Sipila S, Cheng S, Puolakka J, Toivanen J, Suominen H. 2005. The effect of hormone replacement therapy and/or exercise on skeletal muscle attenuation in postmenopausal women: A yearlong intervention. Clin Physiol Funct Imaging 25: 297-304.

Tinetti ME, Fried T. 2004. The end of the disease era. Am J Med 116: 179-185.

Trounce I, Byrne E, Marzuki S. 1989. Decline in skeletal muscle mitochondrial respiratory chain function: Possible factor in ageing. Lancet 1: 637-639.

Umanskaya A, Santulli G, Xie W, Andersson DC, Reiken SR, Marks AR. 2014. Genetically enhancing mitochondrial antioxidant activity improves muscle function in aging. Proc Natl Acad Sci 111: 15250-15255.

Varadhan R, Walston J, Cappola AR, Carlson MC, Wand GS, Fried LP. 2008. Higher levels and blunted diurnal variation of cortisol in frail older women. J Gerontol A Biol Sci Med Sci 63: 190-195.

Visser M, Kritchevsky SB, Goodpaster BH, Newman AB, Nevitt M, Stamm E, Harris TB. 2002. Leg muscle mass and composition in relation to lower extremity performance in men and women aged 70 to 79 : The health, aging and body composition study. J Am Geriatr Soc 50: $897-904$.

Walston J, McBurnie M, Newman A, Tracy RP, Kop WJ, Hirsch CH, Gottdiener J, Fried LP, Cardiovascular Health Study. 2002. Frailty and activation of the inflammation and coagulation systems with and without clinical comorbidities: Results from the cardiovascular health study. Arch Int Med 162: 2333-2341.

Weiss CO, Cappola AR, Varadhan R, Fried LP. 2012. Resting metabolic rate in old-old women with and without frailty: Variability and estimation of energy requirements. $J$ Am Geriatr Soc 60: 1695-1700.

Wilson MMG, Morley JE. 2003. Invited review: Aging and energy balance. J Appl Physiol 95: 1728-1736.

Wolinsky FD, Coe RM, Miller DK, Prendergast JM, Creel MJ, Chavez MN. 1983. Health services utilization among the noninstitutionalized elderly. J Health Soc Behav 24: 325-337.

Xue QL. 2011. The frailty syndrome: Definition and natural history. Clin Geriatr Med 27: 1-15.

Xue QL, Bandeen-Roche K, Mielenz TJ, Seplaki CL, Szanton SL, Thorpe RJ, Kalyani RR, Chaves PH, Dam TT, Ornstein K, et al. 2012. Patterns of 12-year change in physical activity levels in community-dwelling older women: Can modest levels of physical activity help older women live longer? Am J Epidemiol 176: 534-543.

Yates FE. 2002. Complexity of a human being: Changes with age. Neurobiol Aging 23: 17-19.

Zampieri S, Pietrangelo L, Loefler S, Fruhmann H, Vogelauer M, Burggraf S, Pond A, Grim-Stieger M, Cvecka J, Sedliak M, et al. 2015. Lifelong physical exercise delays age-associated skeletal muscle decline. J Gerontol A Biol Sci Med Sci 70: 163-173. 


\section{$\&_{\mathrm{CSH}}^{\infty} \&$ Cold Spring Harbor

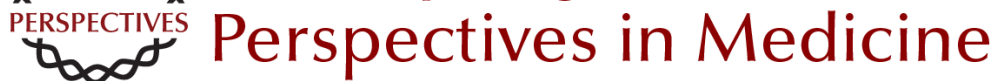

\section{Interventions for Human Frailty: Physical Activity as a Model}

Linda P. Fried

Cold Spring Harb Perspect Med 2016; doi: 10.1101/cshperspect.a025916 originally published online May 3, 2016

\section{Subject Collection Aging}

Personalized Financial Planning Using Applied Genetics

S. Jay Olshansky, Bradley Willcox, Kirk Ashburn, et al.

Biological Restraints on Indefinite Survival Jan Vijg and Steven N. Austad

The Role of the National Institute on Aging in the Development of the Field of Geroscience Felipe Sierra and Ronald A. Kohanski

The Funding Channels of Geroscience Stephanie Lederman

Evolutionary Approaches in Aging Research Melissa Emery Thompson

Interventions for Human Frailty: Physical Activity as a Model

Linda P. Fried

How Research on Human Progeroid and

Antigeroid Syndromes Can Contribute to the

Longevity Dividend Initiative

Fuki M. Hisama, Junko Oshima and George M. Martin

Articulating the Case for the Longevity Dividend S. Jay Olshansky
Funding Life-Extension Research

Mehmood Khan

Influence of Aging Science on Global Wealth

Management Michael Hodin

International Gains to Achieving Healthy

Longevity Andrew Scott, Julian Ashwin, Martin Ellison, et al.

From Life Span to Health Span: Declaring

"Victory" in the Pursuit of Human Longevity S. Jay Olshansky

Crowdfunding and Crowdsourcing of Aging

Science Keith Comito

Inhibition of the Mechanistic Target of Rapamycin (mTOR) -Rapamycin and Beyond Dudley W. Lamming

The Emergence of Geroscience as an Interdisciplinary Approach to the Enhancement of Health Span and Life Span Felipe Sierra

The Economic Promise of Delayed Aging Dana Goldman

For additional articles in this collection, see http://perspectivesinmedicine.cshlp.org/cgi/collection/ 